\title{
Redes Culturales Afro-Latinoamericanas. El caso del Primer Congreso de la Cultura Negra de las Américas*
}

\author{
Afro-Latin American cultural networks. The case of the First Congress of Black Culture of the Americas. \\ Redes culturais afro-latino-americanas. O caso do Primeiro Congresso de Cultura Negra das Américas
}

Eduard Arriaga Arango a

Universidad de Indianápolis, Grecia

arriagae@uindy.edu

ORCID: https://orcid.org/0000-0001-8238-5589

DOI: https://doi.org/10.11144/Javeriana.uh89.rcal

Recibido: 15 Febrero 2020

Aceptado: 23 Julio 2020

Publicado: 20 Diciembre 2020

\section{Resumen:}

El artículo estudia el Primer Congreso de la Cultura Negra de las Américas y su red cultural. A partir de una metodología de análisis de redes complejas, el texto explora cómo dicha red se conecta con la súper-red de representaciones artísticas y de activismo de lo afrolatinoamericano, y, a pesar de ser un nodo débil y tener conexiones débiles, logra alcanzar una posición central en las redes intelectuales y de activismo afrolatinoamericanas. Asimismo, el artículo discute los aportes de las redes culturales como metodología para alcanzar unas humanidades digitales críticas más centradas en la experiencia humana y de producción cultural en una era en la que los algoritmos parecen dirigir nuestra experiencia de la cultura.

Palabras clave: Redes, Afrolatinoamerica, Humanidades Digitales, Congreso de la Cultura Negra.

\section{Abstract:}

The article studies the First Congress of Black Culture of the Americas and its cultural network. Using a methodology of complex network analysis, the text explores how this network connects with the super network of artistic representations and activism of Afro-Latin American and, despite being a weak node and having weak connections, manages to reach a central position in the Afro-Latin American intellectual and activist networks. Also, the article discusses the contributions of cultural networks as a methodology for achieving critical digital humanities, more focused on human experience and cultural production, in an era in which algorithms seem to direct our relations with culture.

Keywords: Networks, Afro-Latin America, digital humanities, black culture congress.

Resumo:

O artigo estuda o I Congresso de Cultura Negra das Américas e sua rede cultural. Partindo de uma metodologia de análise de redes complexas, o texto explora como essa rede se conecta com a super rede de representações artísticas e ativistas dos afro-latinoamericanos e, apesar de ser um nó fraco e ter conexões fracas, consegue se posicionar centralmente para as redes intelectuais e ativistas afro-latino-americanas. Da mesma forma, o artigo discute as contribuições das redes culturais como metodologia para alcançar humanidades digitais críticas, mais focadas na experiência humana e na produção cultural, em uma era em que os algoritmos parecem direcionar nossas relações com a cultura.

Palavras-chave: redes, Afro-América Latina, humanidades digitais, congresso de cultura negra.

\section{Introducción}

Las humanidades digitales como campo interdisciplinar ha sufrido varias expansiones y revoluciones en los últimos veinte años. Desde la construcción básica de infraestructura digital para la investigación humanística, pasando por la discusión sobre sus límites y alcances, hasta la expansión y adaptación no sólo a otros campos del saber humanístico sino a diversas regiones del mundo, este campo se ha caracterizado por altos grados de reflexividad tanto en su base epistemológica como metodológica. Asimismo, los eventos sociales y políticos

Notas de autor

\footnotetext{
a Correo de correspondencia: arriagae@uindy.edu
} 
que han puesto al descubierto el poder real de las herramientas y plataformas digitales para influenciar el comportamiento social, político y cultural de los seres humanos, han provocado que el campo revise sus protocolos con relación a la forma en la que se obtiene, se ordena y se presenta la información, así como con los procesos de colaboración, transmisión de conocimientos y apertura a nuevas formas de representación.

Una de las discusiones más importantes de los últimos años tiene que ver con el futuro del campo y, particularmente, con lo que se ha denominado "humanidades digitales críticas". De acuerdo con David Berry (2014), la ola actual en la que se encuentra inmerso el campo requiere un esfuerzo por desarrollar "métodos, metáforas, conceptos y teorías con relación al software y al código que nos permitan pensar acerca y a través de dichos sistemas, ya que ellos tienen y van a continuar teniendo una gran influencia en la opinión pública y en el ámbito político" (4). En ese sentido, el futuro de las humanidades digitales está más allá del simple uso mecánico de las herramientas digitales. Por el contrario, una visión crítica, creativa y propositiva requerirá que los investigadores cuestionen dichas herramientas y discutan si se pueden o no adaptar a diversos contextos. Pero aún más importante, dicha visión requerirá la posibilidad de rastrear los contactos, evoluciones y adaptaciones que el registro cultural, ya sea análogo o digital, sufre a lo largo del tiempo y el espacio. En ese sentido y siguiendo a Roopika Risam (2019) es importante superar la idea de que dichos registros son "simplemente considerados depósitos de materiales del pasado" (29), sino que debemos comenzar a entender la cultura como una serie de procesos dinámicos en los que hay interacciones complejas entre seres humanos, objetos, instituciones, y contextos, a partir de los cuales la humanidad continúa construyendo sistemas para entender y explicar el mundo.

De acuerdo con lo anterior, es importante pensar una estrategia metodológica y epistemológica que le permita a las humanidades digitales ir más allá de la concepción instrumental de lo digital y, por el contrario, pueda desarrollar mapeos constantes de la dinámica cultural en tanto proceso de intercambios e interacciones. A lo largo de este artículo, mostraré cómo las redes culturales pueden ser una alternativa robusta para el campo en cuestión en función de alcanzar mayores niveles de inclusión y fortalecimiento del aspecto crítico.

Centrado en el análisis de la red cultural del Primer Congreso de la Cultura Negra de las Américas (el Congreso de ahora en adelante) mostraré cómo el uso de las redes culturales en tanto metodología de visualización, análisis y reflexión permiten rastrear relaciones a través de las cuales se iluminan componentes "débiles" o menores del registro cultural. Al ser revisados desde la perspectiva de las redes culturales, tales componentes pueden reclamar su centralidad e importancia en la transmisión de valores culturales. Tal será el caso de países como Colombia o de figuras como Manuel Zapata Olivella que, en el contexto del estudio sobre las culturas afrodescendientes en las Américas (afrolatinoamericanas ${ }^{1}$ ), no son considerados centrales hasta muy recientemente. ${ }^{2}$

Con el fin de alcanzar los objetivos centrales, el texto estará dividido en secciones que le permitirán al lector una mayor compresión del abordaje propuesto. Primero, discutiré el concepto de red cultural como metodología para estudiar las producciones culturales. Segundo, discutiré el caso de la red cultural del Congreso haciendo énfasis en las redes que lo preceden y luego en las que son generadas y se establece a partir del evento. En esta sección discutiré las visualizaciones/experimentos desarrollados a través de herramientas computacionales y basados en la producción textual del Congreso (cartas, memorias, listas de invitados, mesas de trabajo, etc.).

\section{De la red como metáfora a las redes culturales}

La existencia de las redes complejas no es un asunto nuevo ni exclusivo de nuestra realidad tecnológica. Autores como Barabasi (2002), Castels (1996), Reynoso, (2011) o Granovetter (1973), muestran que ellas han hecho parte del vocabulario y de las abstracciones de diversas ciencias desde hace más de cien años. Sin embargo, el desarrollo y materialización de sistemas como el Internet hicieron que el concepto se popularizara 
y fuera ganando más fuerza en diversos contextos sociales. Las redes pueden ser entendidas como sistemas complejos y dinámicos basados en la comunicación y en la relación productiva ya sea entre objetos, personas, instituciones, organismos vivos, fuerzas naturales, o productos simbólicos, entre otros. Estos sistemas son abstraídos por diversas ciencias como la ciencia de redes - una rama de las matemáticas-, en las cuales se piensan los sistemas concretos - por ejemplo, las relaciones sociales- y se representan a través de modelos compuestos por nodos (agentes) que interactúan o establecen vínculos con otros nodos. A su vez, las interacciones o relaciones entre ellos son representadas como líneas de relación (aristas, links, vínculos) que nos permiten saber con quiénes interactúan ciertos agentes o por medio de quién establecen ciertos contactos.

Lo fundamental respecto a las redes es que les permiten a los investigadores desarrollar una visión más abarcadora y conectada con los procesos de auto-organización, complejidad y variedad de escalas en las cuales suceden los fenómenos estudiados por las ciencias, sean naturales, sociales o humanas. El concepto de redes entonces sería la expresión de una "reinterpretación más sustancial" que apunta a pensar los sistemas estudiados en "términos relacionales y contingentes, antes que estructurales y determinados por leyes” (Escobar, 2015, p. 29). Lo fundamental no es detectar un patrón o una ley universal que determine el comportamiento del sistema representado por la red, sino detectar los diversos patrones y comportamientos inesperados que emergen de las relaciones e interacciones entre agentes, nodos o elementos de la misma.

Las ciencias sociales y, particularmente, las investigaciones centradas en los movimientos sociales afrolatinoamericanos han usado el concepto de red para identificar las interacciones de grupo, entendiéndolas como "acumulación de fuerzas" (Agudelo, 2010, p. 78) a través de las cuales se busca alcanzar un fin. A partir de esa metodología ha sido posible explicar cómo han funcionado y continúan funcionando las estructuras de organización y activismo de tales comunidades en las Américas. Sin embargo, la mayoría de análisis se han basado en identificar e imaginar cómo se relacionan los nodos más prominentes de las redes (líderes) a partir de diversos tipos de información intercambiada. En algunos casos, tal información es anecdótica o en otros la estructuración de la misma no permite "visualizar" la forma en la que se comporta la red, limitando al observador a enfocarse en los nodos y relaciones que parecen ser más significativas, y dejando desatendidos otros lazos débiles (Granovetter, 1973; Peter, 2006) y nodos aparentemente pequeños.

Otra de las críticas al análisis y uso de la red como metáfora e interface para analizar la forma en la que la sociedad civil (incluyendo productores profesionales y no profesionales ${ }^{3}$ ) transmite y produce cultura tiene que ver con el poco desarrollo y estructuración que dichos análisis han tenido en contextos como Latinoamérica (Delfin, 2013, p. 241). En dicho espacio geográfico y en campos como los estudios latinoamericanos y afrolatinoamericanos, se evidencia falta de aproximaciones exhaustivas y que vayan de lo descriptivo a explicar cómo se forman y cómo funcionan dichas redes.

\section{La red cultural como metodología: de la red artística de lo afrodescendiente a la red del Primer Congreso de Cultura Negra de las Américas}

De acuerdo con las críticas y limitaciones señaladas, es importante considerar una metodología basada en una formalización mayor a partir de la cual se puedan entender las dinámicas culturales estudiadas. En ese caso, proponemos las redes culturales como metodología y aproximación. Dicha formalización aprovecha el poder de herramientas digitales y estructuras computacionales, mediante las cuales se pueden identificar relaciones, así como patrones, comunidades y comportamientos sistémicos. Asimismo, esta metodología le permite al investigador conectar una cantidad significativa de información cultural en la que los agentes y conectores débiles puedan ser visibilizados.

Para desarrollar el proceso metodológico centrado en las producciones culturales afrolatinoamericanas fue fundamental concebirlas (abstraerlas) como redes culturales. Es decir, como redes en "las que las relaciones humanas están mediadas por objetos, fenómenos, acciones y representaciones consideradas culturales para 
un grupo dado" (Suárez et al., 2015, p. 96). Este tipo de abstracciones nos permiten entender no sólo cómo se generan las conexiones entre los agentes (nodos) sino cómo dichas conexiones estarán siempre mediadas por objetos cargados con valores simbólicos a partir de los cuales se pueden generar acciones y mensajes adicionales.

Los eventos denominados culturales suceden en el tiempo y en el espacio, desapareciendo al ser completados, pero dejando trazos en documentos, objetos, y memorias producidas por/en los sujetos involucrados. En ese sentido, la metodología se basa en la revisión de documentos (visuales, sonoros, textuales, etc.), la categorización de los mismos mediante la creación de bases de datos relacionales, la visualización de dichas bases mediante herramientas digitales y, finalmente, el análisis y reflexión sobre la información. Uno de los elementos más importantes de la metodología tiene que ver con la categorización de la información. Las categorías se construyen y definen dependiendo de la idea perseguida por el investigador y tratando de respetar cuanto sea posible el objeto investigado y los elementos que interactúan como parte de él.

Esta estructura metodológica fue usada inicialmente en 2011 para analizar y visualizar lo que Suárez et al. (2015), han denominado una "red súper-compleja" (98) centrada en la transmisión de información cultural afrodescendiente en las Américas: "la red artística de lo afrodescendiente" (Arriaga, 2015, p. 289; Arriaga, 2018, p. 284). ${ }^{4}$

La forma de visualizar dicha "red súper-compleja" fue a través de experimentos llevados a cabo con herramientas computacionales, particularmente Wandora ${ }^{5}$, para extraer información de diversos textos (críticos, literarios, políticos, de activismo, etc.). Después de generar una estructura de categorías básicas (ej. personas, instituciones, relaciones), y unas reglas básicas (ej. el objeto texto no puede producir personas, pero el objeto persona sí puede producir textos; un objeto persona puede ser considerado una institución dependiendo de sus conexiones, etc.) comenzamos a generar la visualización de la información, dando como resultado "La red artística de lo afrodescendiente" (Figura 1 y 2). En esa visualización se representan relaciones entre obras (color lila), países (color rosado), creadores (color verde) y relaciones (en este caso las aristas que unen a los nodos). A partir del modelo construido con un equipo de trabajo interdisciplinar y de la lectura contextual de los materiales, arribamos a algunas conclusiones parciales como: a) países como Cuba y Estados Unidos ocupan un lugar prominente en el procesos de diseminación de los valores y representaciones afrolatinoamericanas; b) los creadores y el discurso literario también son prominentes (ej. Nicolás Guillén) y han marcado la forma en la que la red se ha comportado y la forma en la que los discursos artísticos sobre lo afrolatinoamericano se han transmitido, percibido y representado.

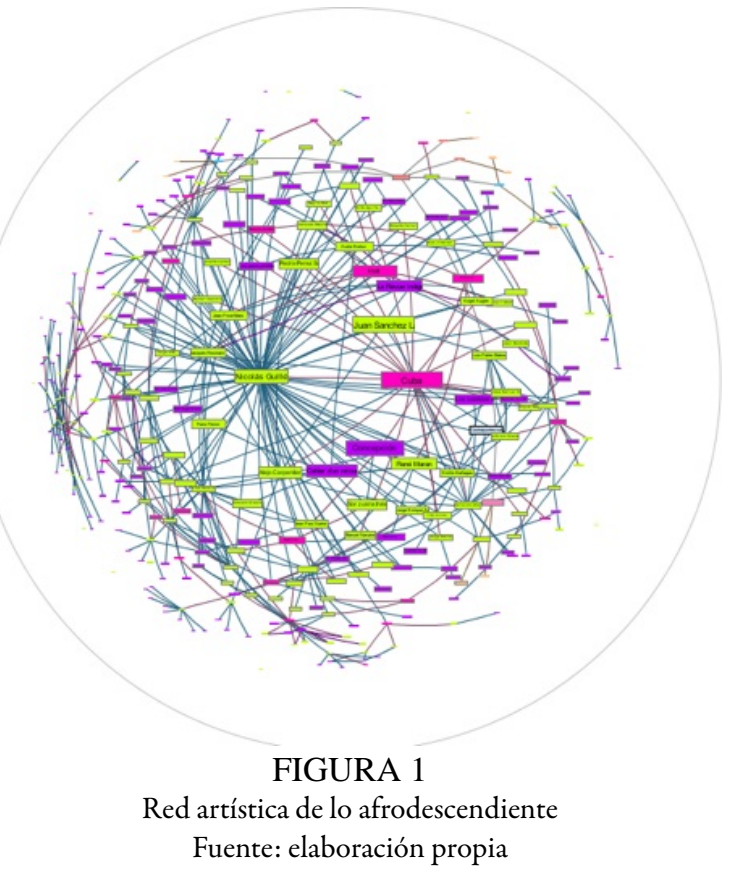




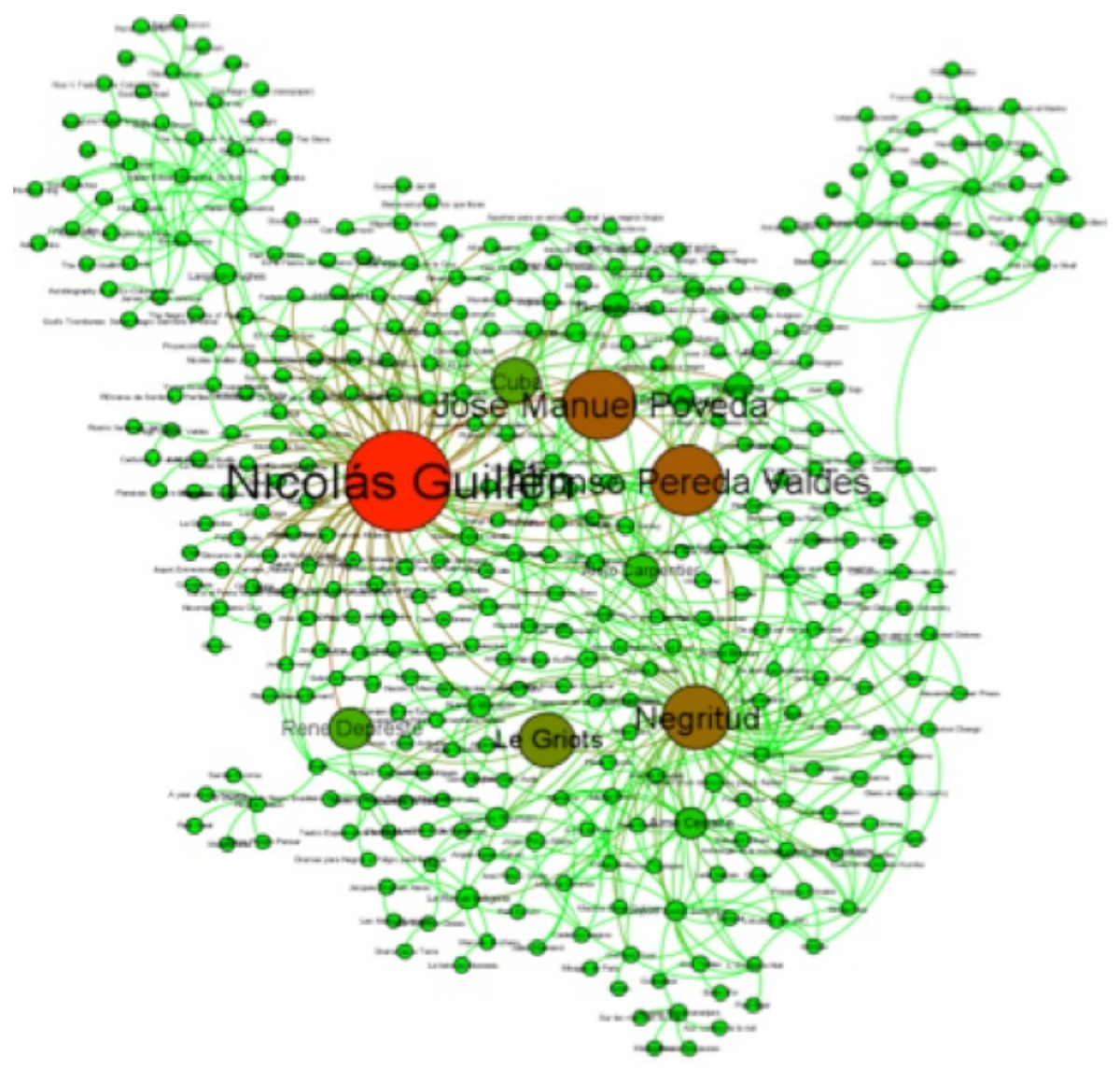

FIGURA 2

Red artística de lo afrodescendiente. Centralidad Fuente: elaboración propia

En el caso de la información relativa al Congreso, lo que se buscaba era identificar las redes culturales. Así, entonces, los textos fueron revisados atendiendo a categorías como persona, institución (ya sea un país, una universidad, un movimiento social, político, cultural o artístico, etc.) y las relaciones entre cada uno de los elementos. Después de establecer tales categorías, los textos mencionados comenzaron a ser leídos a través de lecturas tradicional (la lectura cercana de las humanidades y las ciencias sociales) y computacional (Natural Language Processing), particularmente a través de la caja de herramientas de análisis de lenguaje natural (Natural Language Toolkit) de Python ${ }^{6}$. Gracias a estas herramientas digitales y a la anotación manual se pudieron extraer los nombres de personas e instituciones, así como las relaciones existentes entre cada uno de ellos, generando la base de datos a partir de la cual se hacen las visualizaciones.

La información para construir el modelo "La red del Primer Congreso de la Cultura Negra de las Américas" (Figura 3) se extrajo a partir de textos (actas, listado de asistentes, cartas, panfletos y material publicitario, etc.) que pertenecen al fondo Manuel Zapata Olivella, digitalizado en buena parte por la Universidad de Vanderbilt en Estados Unidos, así como de textos adicionales que pertenecen al ecosistema literario y de activismo afrcolombiano y afrolatinoamericano. El modelo nos permite ver las relaciones e interacciones textuales del congreso como un sistema complejo de coordinaciones en busca de un objetivo claro: discutir y resolver los problemas de las comunidades negras de las Américas. Lo interesante de este modelo es que, en cierta medida, cuestiona la súper-red generada en 2011 ("La red de representación artística de lo afrodescendiente") en donde locaciones como Colombia y Panamá o agentes como Manuel Zapata Olivella o Abdias Do Nascimento no se encontraban dentro de los nodos determinantes. Estos nodos débiles ganan centralidad en la medida en la que se ajusta la escala de observación. 


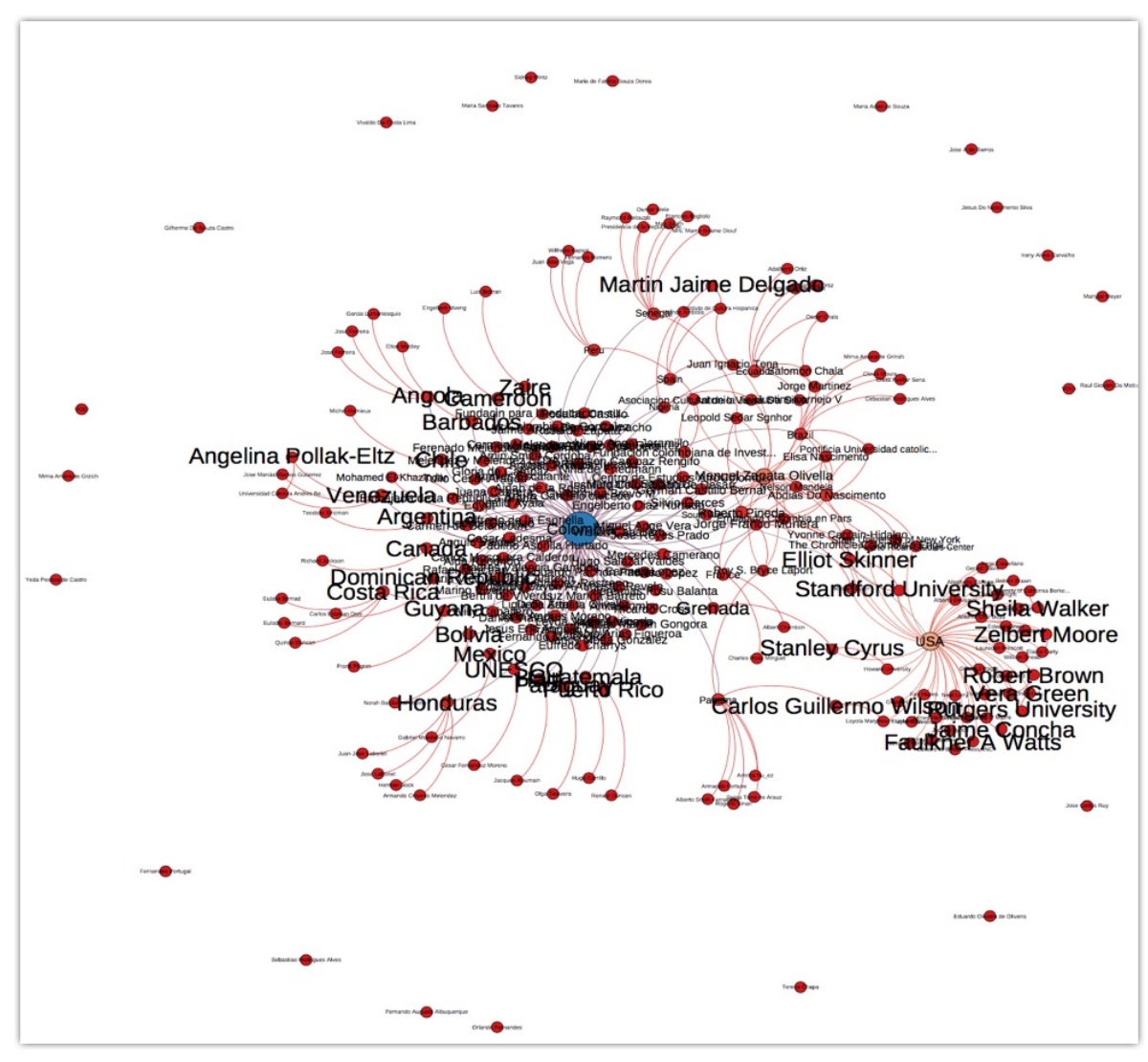

FIGURA 3

Red Primer Congreso de la Cultura Negra de las Américas

Fuente: elaboración propia

Otra diferencia entre la metodología usada para generar la red del Congreso y la del modelo inicial tiene que ver con las herramientas digitales y computacionales usadas. En la red del Congreso, en vez de usar Wandora, usamos $\mathrm{Gephi}^{7}$, una aplicación con menos versatilidad a la hora de coleccionar información, pero mayor flexibilidad con relación al análisis estadístico de redes complejas. Este tipo de análisis permite visualizar relaciones más complejas y ajustar la escala para visibilizar agentes que han sido invisibilizados pero que tienen peso en la dinámica del sistema. Eso es precisamente lo que sucede con la red del Congreso: desde la perspectiva de la súper-red, los nodos y relaciones del Congreso eran débiles e invisibles. Al ajustar la escala, sin embargo, vemos como el modelo muestra no sólo relaciones interesantes entre diversos nodos, sino que nos permite conectar la imagen con procesos epistemológicos y sociales a partir de las cuales se volvió a poner sobre la agenda global el problema de la discriminación, el racismo y el reconocimiento de los afrodescendientes como pueblo diaspórico complejo.

\section{El Primer Congresos de la Cultura Negra de las Américas como red cultural compleja}

Los Congresos de la Cultura Negra de las Américas, inaugurados en Cali, Colombia en 1977 y con capítulos en Panamá (1980), San Pablo (1982) y un cuarto planeado, pero jamás desarrollado, son considerados un punto de quiebre en la historia de la diáspora africana en las Américas. De acuerdo con el intelectual y político afrobrasileño, Abdias do Nascimento, el primer congreso -y los subsecuentes- "fue un hito en la historia africana dado que fue la primera reunión en la cual la gente negra de las Américas se encontró después 
de cuatrocientos años de estar en el nuevo mundo." (Nascimento, 1979, p. 15). Los congresos fueron el resultado de un esfuerzo colaborativo entre intelectuales, activistas, académicos y diversas instituciones a nivel internacional, cuya idea fundamental fue el estudio de las experiencias complejas de los afrodescendientes en el contexto de las Américas. Esto se desarrolló como una posición política en contra de la Guerra Fría, del Apartheid, y en general del colonialismo y neocolonialismo ejercido en todos los frentes, particularmente el referente al estudio del "aporte africano en el continente" (Primer Congreso, 1977b, p. 2). El ejemplo más claro aparece en el documento de convocatoria al Congreso surgido de la reunión previa llevada a cabo en Cartagena de Indias, Colombia, del 19 al 22 de diciembre de 1976. Este documento abre con una "invitación a la desalineación" (Primer Congreso, 1977b, p. 2) como forma de contrarrestar los bloques --occidente (Estados Unidos y los aliados) y oriente (El bloque Soviético)- fundamentales para la Guerra Fría, así como sus efectos en la cultura del mundo y, especialmente, en Latinoamérica y el Caribe.

Los Congresos comienzan a desarrollarse como una forma de buscar autonomía y autoevaluar la situación de las comunidades negras y de la diáspora africana en el continente americano. Es precisamente la idea de devolverle la agencia a los sujetos afrodescendientes la que direcciona la realización de un congreso en el que se cuestionan los estudios, las interpretaciones históricas y las aproximaciones científicas al fenómeno de la diáspora africana. Desde la visión de los organizadores del evento, los enfoques "del proceso esclavista visto como una crónica de sucesos naturales ocurridos sin la voluntad de los conquistadores, distorsionan la realidad histórica y pretenden justificar las injusticias sociales sufridas por los descendientes de africanos en la sociedad americana (Primer Congreso, 1977b, p. 3).

La forma de corregir tales errores es a través del diálogo, de una ciencia crítica y de la organización política basada en un conocimiento que iba más allá de las estructuras tradicionales. Es por ello que el Congreso buscaba "precisar, en la gran familia de investigadores, artistas, escritores, profesionales y empíricos, las filosofías y objetivos democráticos de la acción científica y social que orienten la creatividad de los negros, mulatos, y zambos de las Américas" (Primer Congreso, 1977b, p. 4). Es decir, el Congreso fue ideado como punto de encuentro para compartir las diversas experiencias de los afrodescendientes y generar una agenda que fuera más allá de la academia como espacio enajenado y, en ciertas circunstancias, opuesto a los objetivos de una descolonización cultural.

La mejor forma de garantizar estos objetivos fue a través de la antropología como ciencia del hombre, de su diversidad y de sus construcciones más creativas. En ese sentido, las memorias del evento señalan que dicha ciencia guiará la planeación, implementación y desarrollo del mismo, ya que ella "entiende al hombre como una célula multicreadora que no solo genera valores culturales, sino que sea cuales fueren las condiciones sociales impuestas, debe generar permanentemente nuevos aportes" (Primer Congreso, 1977b, p. 4). En ese sentido, los afrodescendientes de las Américas, eran entendidos como sujetos creadores que, a través de procesos culturales y, a pesar de la opresión, han logrado generar estrategias y formas culturales para proponer nuevas formas de ser, de ver y de actuar.

\section{El ecosistema de las redes previas}

La idea de los congresos no se generó en el vacío. Por el contrario, éstos deben entenderse como el resultado de complejas interacciones entre agentes, estructuras de comunicación, en unos ecosistemas determinados que condicionaron la realización o emergencia de los mismos. Desde la perspectiva de la teoría de la complejidad, los congresos evidencian las características fundamentales de un sistema complejo (Francis Heylighen, 2009, p. 3). ${ }^{8}$ En el caso de las redes previas, hay dos que consideramos fundamentales en la emergencia del Congreso y su red asociada: La del Club del Negro y la del Día del negro. Ellas, a su vez, emergen de redes culturales que funcionan a diferentes niveles -local, regional, nacional etc. Asimismo, la interconexión internacional se 
convierte en un elemento fundamental --aportado por viajes, comunicaciones e interacciones hemisféricaspara generar una red cultural que, como la del Congreso, se vuelve transnacional, colaborativa y solidaria.

La interconexión con otros intelectuales y con activistas en función de exaltar y re-centrar la figura de la cultura negra a nivel local, nacional e internacional comienza ya a manifestarse en la creación del "Club Negro de Colombia" y la celebración del "Día del Negro" (Zapata Olivella, 1990, p. 187-190) ${ }^{9}$. Esta celebración, ambientada con música de cantantes negros norteamericanos como Marian Anderson y Paul Roberson, es una muestra de la conexión que los intelectuales afrocolombianos tenían con las ideas de un movimiento negro globalizado. Un movimiento diseminado a través de documentos, pero, al mismo tiempo, experimentado de primera mano a través de organizaciones cívicas que intentaban buscar alternativas en contextos coloniales como Cartagena, Bogotá, Cali, Popayán, etc. Este evento, organizado por Natanael Díaz, Helcías Martán Góngora, Marino Viveros, Víctor M. Viveros, Manuel Zapata Olivella y Delia Zapata Olivella, además de otros estudiantes negros de diversas regiones (Prescott \& Tilis, 2006, p. 11) comienza a marcar la forma de ver las relaciones raciales en el país por parte de estos intelectuales y activistas. Asimismo, el evento los prepara para desarrollar un camino que se volverá más complejo con cada experiencia. De acuerdo con el mismo Manuel Zapata Olivella (1956), la realización del "Día del Negro" (1943) y la consecuente fundación del Club Negro de Colombia estaban dirigidas a "exaltar la participación del negro en nuestra nacionalidad" (p. 32).

Aunque el Club Negro no se consolidó como una institución de larga duración en el ámbito local o nacional, la idea misma desencadenó procesos de más largo aliento a partir de los cuales se comenzó a cuestionar la falta de inclusión de las comunidades negras en la estructura social y el discurso intelectual (como discurso íntimamente conectado al poder). Cuatro años después, en 1947, Zapata Olivella, junto con Natanael Díaz y Marino Viveros, fundan el Centro de Estudios Afrocolombianos (Pisano, 1977, p.191). La creación de dicho espacio se establece como un avance fundamental en la representación de las comunidades afrocolombianas, ya que se hace bajo el auspicio del Instituto Etnológico Nacional, agencia dedicada al estudio de las culturas ancestrales del país -léase, los indígenas-, pero con poca cabida para el reconocimiento de los afrodescendientes como sujetos históricos y culturales que determinaron el rumbo de la nación. Manuel Zapata Olivella, Natanael Díaz y Marino Viveros, junto con la red local y nacional de estudiantes, escritores y activistas, lograron poner en la agenda nacional de la época el asunto de lo afrocolombiano. Dicho logro será, en cierta medida, un modelo a escala de lo que sucederá a partir de 1977 con los congresos de la cultura negra y con toda la red del movimiento negro de las Américas.

La red a partir de la cual emergen el Club Negro de Colombia y del Centro de Estudios Afrocolombianos está basada en la participación de estudiantes, artistas, políticos y activistas negros en Bogotá, pero conectados (nacidos o con tradición familiar) a regiones que, automáticamente, se asocian con la existencia de las comunidades negras (las costas del Mar Pacífico y Caribe). Con base en los textos que documentan el evento, fue posible desarrollar una visualización (Figura 4) a partir de la cual se evidencia la centralidad de algunos de los actores. Entre más central e importante para la red (en términos de conexiones y posibilidades de transmitir mensajes y producir efectos en otras redes a nivel local, nacional e internacional) los nodos se harán más rojos. Asimismo, los nodos amarillos hacen parte de la red, pero no son protagonistas en la medida en que no han recibido igual nivel de atención por parte de la documentación centrada en el Club o, en su defecto, no estaban tan bien conectados en el ecosistema social que el modelo representa. En ese sentido, hay dos nodos/agentes fundamentales: Natanael Díaz y Manuel Zapata Olivella. Díaz, nacido en Puerto Tejada (Cauca 1919-1964) es uno de los líderes del movimiento afrocolombiano que ha recibido menor atención por parte de la historiografía nacional y cuya marca se extiende también hasta nuestros días. El mismo Zapata Olivella (1990) reconoce el vanguardismo de Díaz, admitiendo que él debería ser considerado el "precursor de la Negritud en Colombia” (p.183). Zapata Olivella, por su parte, comenzará a mostrar un protagonismo siendo un estudiante universitario al igual que Marino Viveros y otros de los actores representados aquí- que será trasladado a sus otras empresas artísticas, políticas e investigativas. 


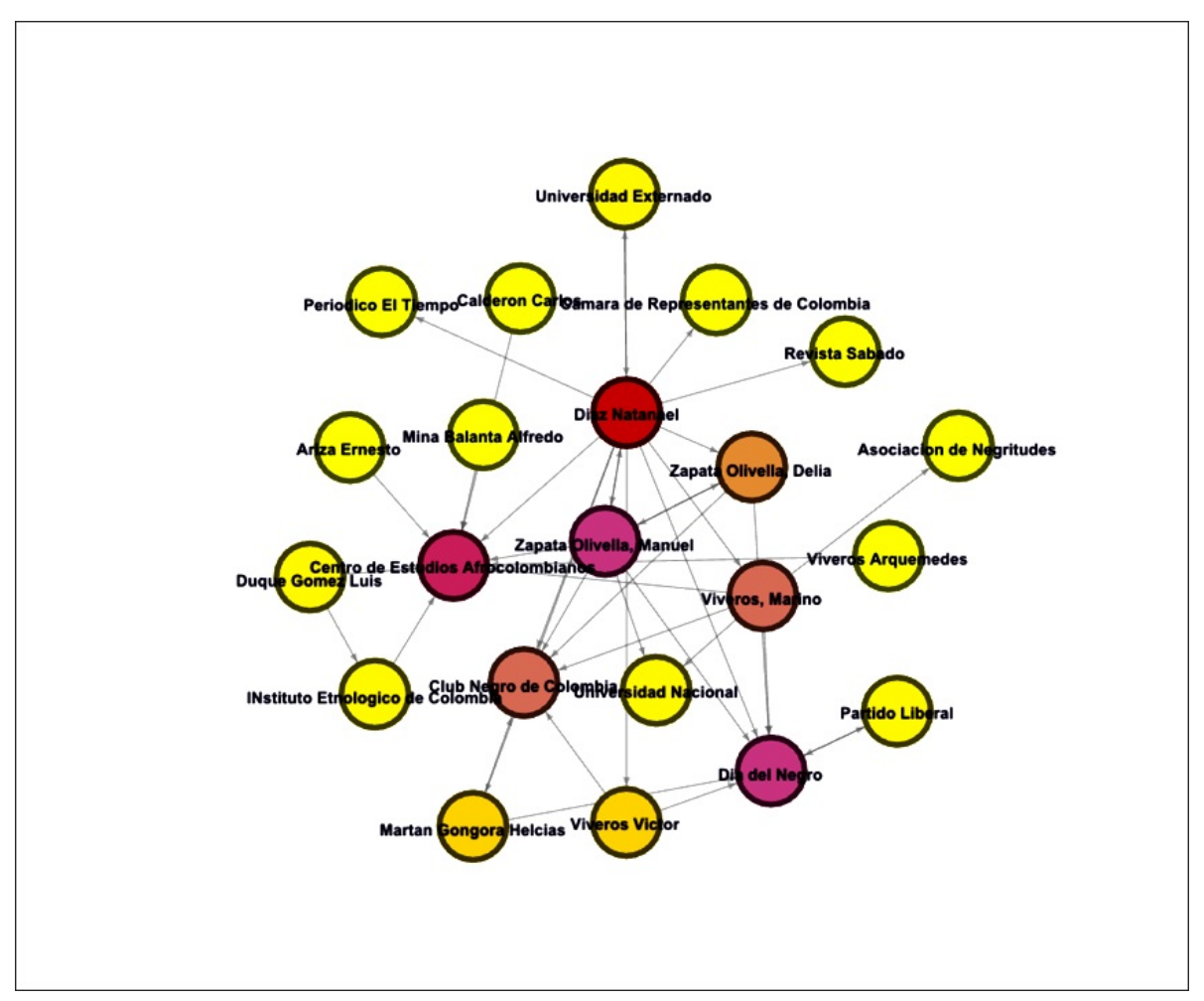

FIGURA 4

Club del Negro. Centralidad

Fuente: elaboración propia

Dentro de la red, otros nodos que tienen un nivel similar de centralidad (similar tonalidad de rojo) a Zapata Olivella y Díaz son el Club Negro de Colombia, el Día del Negro y el Centro de Estudios Afrocolombianos. Es claro que estos tres nodos (categorizados como instituciones) deben ser centrales porque son el objeto que los demás agentes e instituciones buscaban consolidar con los eventos realizados. En la categoría de persona, otros nodos de similar nivel dentro del modelo serán Marino Viveros y Delia Zapata Olivella. Al igual que Manuel Zapata, Marino Viveros era un estudiante para ese momento. A pesar de ser nombrado el presidente del Club (Mera Villamizar, 2008, p.10) y de participar en la consolidación de la red para el desarrollo del Congreso, Marino no recibe la misma atención que Díaz o que Manuel Zapata Olivella. Igual sucede con Delia Zapata Olivella, quien, dentro del modelo, se representa como una agente (un nodo) secundaria. Sin embargo, a medida que pasa el tiempo y a través de procesos sensoriales y performativos como la danza, comienza a ser fundamental para los movimientos negros afrocolombianos y, específicamente, para la formación misma de Manuel Zapata Olivella como líder natural del movimiento a nivel de las Américas ${ }^{10}$.

$\mathrm{Al}$ revisar el modelo, es claro que la importancia de Manuel Zapata Olivella podría considerarse como de menor nivel. El nodo central, como ya lo comentamos, lo ocupa Díaz, mientras que Zapata Olivella estaría en un tercer nivel detrás del "Centro de Estudios Afrocolombianos." Sin embargo, las relaciones, interacciones y experiencias que comenzará a adquirir a partir de los viajes, oficios, lecturas y amistades/colaboraciones, marcarán la expansión de una red que pasará del nivel local (con intereses transnacionales representados en la idea de traer la protesta por el racismo contra los afroamericanos de los Estados Unidos a Colombia) a un nivel internacional e intercontinental.

Un año después de desarrollar las actividades del Día del Negro, Zapata Olivella emprende un viaje de reconocimiento, descubrimiento y auto-descubriemiento que, seguramente, le amplía la perspectiva y le permite incrementar y desarrollar las conexiones (Díaz-Granados, 2003, p.14-20; Prescott, 2007, p. 22-23; Zapata Olivella, 2000, p.108-109, 112-113) para pensar y aportar a un evento de las magnitudes y alcances 
del Congreso. Coincidente con el viaje del escritor cordobés a México ${ }^{11}$, en la capital de ese país se lleva a cabo la inauguración del Instituto Internacional de Estudios Afroamericanos que se establece como punto de partida para lo que contemporáneamente conocemos como estudios afrolatinoamericanos. El instituto contaba con figuras como Fernando Ortiz, Gonzalo Aguirre Beltrán, Melvin Herskovits, Nina Rodrigues (Ortiz,1944b, p.1) entre otros, preocupados por entender y reconocer las contribuciones del elemento africano a la construcción de las culturas de las Américas. El Instituto emergió de la discusión al interior del Congreso Etnográfico de México, llevado a cabo en 1944. Allí, Gonzalo Aguirre Beltrán junto a otros intelectuales de la región reclamaron la inclusión del componente africano en el estudio de la cultura nacional y su evolución en función de la modernización (Ortiz, 1944ª p. 2). Aunque no hay una referencia directa sobre el contacto, para ese momento, entre Zapata Olivella y alguno de los intelectuales involucrados en la creación del Instituto o con los discursos sociales que se generaron a partir del mismo, sí es claro que las experiencias del escritor colombiano fueron impactadas por la interacción con la intelectualidad mexicana, así como con intelectuales migrantes en México.

La red que se comienza a desarrollar gracias al paso de Zapata Olivella por México es similar a la que se generará en Estados Unidos donde el escritor afrocolombiano tuvo interacción con poetas como Langston Hughes, así como con migrantes y sujetos marginales que le permitirán entender la complejidad de lo cultural y lo identitario (Díaz-Granados, 2003, p. 20; Zapata Olivella, 1953, 24). Estas redes previas y, en cierta forma, los procesos de interacción internacional, aportarán al desarrollo de la red cultural del Congreso; una red rica no sólo en participantes y relaciones sino en epistemologías que intentan descolonizar la forma de representar, estudiar y abordar la presencia del pueblo negro en las Américas.

\section{La red del Congreso en primer plano}

En el documento guía del Congreso es claro que el evento intenta conectar diversas formas de pensar y aproximarse a los problemas de la cultura negra en las Américas. De acuerdo con eso, los organizadores hacen un llamado a "los investigadores de las ciencias humanas, artistas, escritores, profesionales y trabajadores empíricos (artesanos, médicos tradicionales, luchadores cívicos, etc.) comprometidos con la descolonización cultural, científica y social del aporte africano en el continente..." (Primer Congreso, 1977b, p. 1). Basados en esa idea central, y siguiendo la metodología propuesta, desarrollamos la sistematización de la información a partir de la cual se genera el modelo (red) computacional que nos ayuda a entender el funcionamiento de la red del Congreso.

Mediante la lectura cercana de documentos (ej. la guía de participación, las memorias sobre cada una de las ponencias o las cartas que se usaron como método para contactar participantes y sujetos interesados) fue posible identificar una estructura con diferentes niveles de participación y compromiso. Por ejemplo, el documento guía mencionado anteriormente propone que, "habrá cuatro categorías: invitados, asistentes, observadores, y adherentes." (Primer Congreso, 1977b, p. 5). Así, los invitados serán los representantes de cada uno de los países a quienes la organización pagaría los gastos; los asistentes todos los interesados en asistir y cuyos gastos correrían por cuenta propia; los observadores, por su parte, asistentes sin voz ni voto; y, finalmente, los adherentes todos aquellos que se adhirieran a los principios del Congreso y, que sin importar si asistieran o no, manifiestan su apoyo al evento a través de "declaraciones, conferencias, manifiestos, cartas, telegramas, [y] otros medios expresivos que conduzcan a la descolonización” (Primer Congreso, 1977b, p. 5). De acuerdo con estas categorías, algunos participantes destacados fueron entre otros: Jorge Franco Múnera, Yvonne Captain-Hidalgo, Elliot Skinner, Germán Castillo, Vera Green, Mohamed El-Khazindar, Sheila Walker Abdias Do Nascimento, Adalberto Ortíz, Laurence Prescott, Nina S. Friedmann etc., (como invitados); Eduardo Pachón Padilla, Nero López, Hugo Salazar Valdés, Quince Duncan, Jaime Arocha etc., (como asistentes y observadores); y Nelson Mandela, Leopold Sedar Senghor, State University of New 
York, Roy S. Bryce Laport, Charles Wright, etc., (como adherentes). Todos estos participantes junto con las instituciones a las que representan comienzan a desarrollar interacciones que enriquecen la red y hacen posible el Congreso y las subsiguientes actividades que se generarán en el tiempo y en el espacio.

En cuanto a lo que podría denominarse la red epistemológica del Congreso, es claro que el mismo se centró en dos valores fundamentales: la agencia de los pueblos afrodescendientes y la creatividad que los mismos evidenciaron en el proceso de dispersión, esclavización y asentamiento en espacios geográficos y culturales. Estos dos valores básicos estaban a su vez encaminados hacia desarrollar el gran objetivo: la descolonización cultural y la re-configuración de los estudios, producción, representación y consideración histórico política de las culturas afrodescendientes o negras de las Américas. Dicha descolonización consistía, principalmente, en cuestionar el papel de las élites intelectuales de la región y su complicidad en la pobre representación del componente afrodescendiente. Por tal motivo, el Congreso considera que no debía haber una mediación de los intelectuales como se había hecho tradicionalmente, sino que el ideal era generar un espacio de conocimiento para "los pueblos trabajadores, marginalizados, analfabetas incluso para trabajar con ellos hacia una verdadera revolución” (Primer Congreso, 1977h, p. 1).

La idea de la descolonización no se queda solamente en la crítica y separación de los intelectuales blancos y consagrados de la región. Por el contrario, dicho objetivo cobijó también proyectos propios que, como la Negritud, eran faros seguidos por las comunidades negras de las Américas. En ese sentido, el Congreso considera que la idea que debía mover la cultura afrodescendiente de la región no se trataba "de una vuelta en masa al continente africano", como proponía la Negritud en tanto movimiento "sino de la identificación con la cultura negra, defendiéndola en cualquier lugar donde esta cultura esté presente." (Primer Congreso, 1977h, p. 2). De acuerdo con esto, se aprobó que se "considere la Negritud como una estrategia alternativa de participación y reclamo de derechos en Colombia y otros países asistentes al congreso." (Primer Congreso, 1977h, p. 2). Es decir, lo que comenzó como un movimiento poético centrado en la revisión de la representación de los pueblos negros en el arte, el Congreso lo convirtió en una agenda política adaptada a las necesidades, derechos e imaginarios nacionales en función de una conectividad transnacional.

Todas estas ideas, valores y elementos político-culturales acordados por los asistentes y organizadores del Congreso se concretan tanto en la red que surge, como en los proyectos y propuestas que, a corto, mediano y largo plazo generarán redes adicionales. Por ejemplo, una de las propuestas que emergen es la idea de crear un organismo central confederado -algo similar a las Naciones Unidas- centrado en estudiar, abogar y defender las comunidades afrodescendientes en la región. De acuerdo con las actas del evento, dicho organismo debería ocuparse de tres frentes fundamentales: "político (acción), cultural (relativo a la ciencia, el arte y la economía), y el desarrollo tecnológico" (Primer Congreso, 1977h, p. 3). Aunque el organismo descrito parece no haberse concretado nunca, la idea misma sirve de base para redes culturales y de activismo afrodescendiente que se organizarán a finales del siglo XX y que insertarán el tema en la agenda global.

Toda esta información además de las listas de asistentes, de las cartas entre participantes, así como las actas y las conclusiones fueron fundamental para desarrollar una lectura distante ${ }^{12}$ que permiten un mejor entendimiento del Congreso como red y de los eslabones débiles del mismo. Siguiendo la metodología descrita al principio, la información documental fue categorizada, dando como resultado una base de datos. Estos datos fueron visualizados a través de $\mathrm{Gephi}^{13}$, generando un grafo (la representación gráfica de la red) al que se aplicaron diversas funcionalidades estadísticas como: centralidad (para determinar cuál o cuáles nodos son más centrales por el número de relaciones y, por lo tanto fundamentales para el desarrollo y sostenimiento de la red), coeficiente de conexiones (determinando el número de conexiones de cada nodo y su promedio relativo en función del total de conexiones de la red), formación de clusters o grupos (determinando la formación de comunidades a partir de las cuales se pueden explicar y entender algunos patrones y comportamientos de la red), etc. En el caso los experimentos desarrollados, la herramienta fue programada para que los nodos con mayor importancia fueran representados como más grandes (mayor tamaño) y con un color predeterminado (en este caso, color azul). En las redes, la importancia de los nodos 
se mide por el número de conexiones con relación al promedio de conexiones totales existentes en la red. Es decir, la importancia es un asunto estadístico (lectura distante) a partir del cual la interpretación textual y contextual (lectura interpretativa) cobra mayor sentido.

En el caso de la Red del Congreso de la Cultura Negra de las Américas (Figura 3), el nodo más importante en términos de centralidad fue Colombia, mientras que el segundo fue Estados Unidos. Esto quiere decir que el evento, a pesar de ser considerado transcontinental, realmente fue el producto de la conexión entre estas dos naciones. La centralidad de Colombia se puede explicar por dos razones básicas: 1) es la sede tanto del evento como de las reuniones preparatorias; y 2) la mayoría de los participantes estaban conectados con el país ya sea por origen o porque viven en el mismo. En cuanto a Estados Unidos, es el segundo nodo de mayor importancia porque aporta un gran número de participantes. No todos son originalmente estadounidenses de nacimiento (como el caso de Abdias do Nascimento) sino que están afiliados a instituciones de ese país (especialmente universidades) interesadas en la relación con las comunidades negras de las Américas y, en especial, con los movimientos sociales que comienzan a ser fundamentales para la consolidación de una agenda hemisférica afrodescendiente. Otro nodo de importancia es Brasil que, a pesar de no aportar tantos participantes como los otros dos países, logra conectar a varios miembros de la red y diseminar el mensaje que propone el Congreso. Este puede ser considerado uno de los nodos débiles dentro de la red, pero que a medida que pasan los años y los procesos preparatorios de los congresos posteriores, logrará consolidarse como foco a partir del cual se diseminará la información que la red esperaba transmitir ${ }^{14}$. La razón fundamental para la ausencia de mayor número de participantes brasileños en el congreso, de acuerdo con Abdias Do Nascimento (1978) tuvo que ver, básicamente, con la negativa de ese gobierno de apoyar a la delegación invitada y, a través de una "manipulación burocrática" hizo evidente el proceso de genocidio físico y simbólico que los gobiernos brasileños han llevado a cabo sobre el pueblo afrobrasileño $(\mathrm{p} .15)^{15}$. 


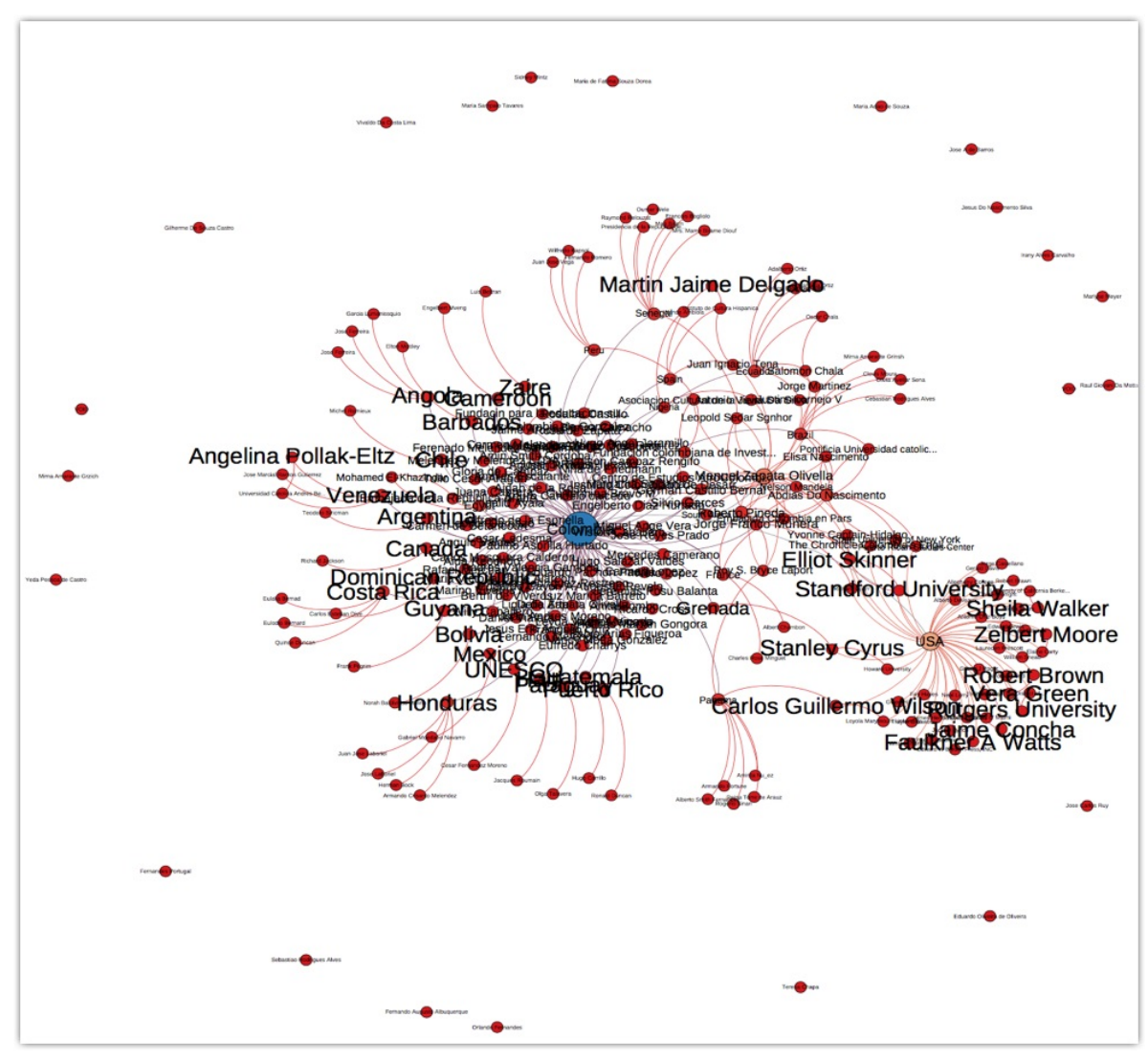

FIGURA 3

Red del Congreso de la Cultura de las Américas

Fuente: elaboración propia

Pero lo que la visualización de la red revela respecto a la centralidad de Colombia no es sorprendente. Por tal motivo, fue importante realizar un segundo experimento eliminando tal nodo y revisando la centralidad de otras instituciones o personas en la diseminación de la información. La imagen resultante (Figura 5) nos permite ver varios elementos interesantes: 1) la eliminación del nodo Colombia deja a muchos nodos sin un vínculo directo con la red. Es posible que Manuel Zapata Olivella u otros organizadores o agentes centrales de la red haya tenido contacto previo con ellos, sin embargo, en el archivo investigado no hay prueba de esas conexiones. Por tal motivo, cuando se elimina el nodo, los participantes quedan si una conexión clara. 2) Se genera una pequeña comunidad (una pequeña red dentro de la red), ubicada en la parte derecha de la visualización. En esa sub-red (Figura 6), el nodo central es Manuel Zapata Olivella, quien, siguiendo la lógica de la centralidad explicada anteriormente, se convierte en el nodo azul (mayor centralidad relativa de conexión), adquiriendo la importancia que ya se vislumbraba en la red de la celebración del Día Negro y la de la creación del Club Negro. 3) Surgen otros nodos adicionales como Abdias do Nascimento (realmente importante para el movimiento negro de las Américas y, particularmente para los Congresos) y se mantienen Estados Unidos y sus asociados. 


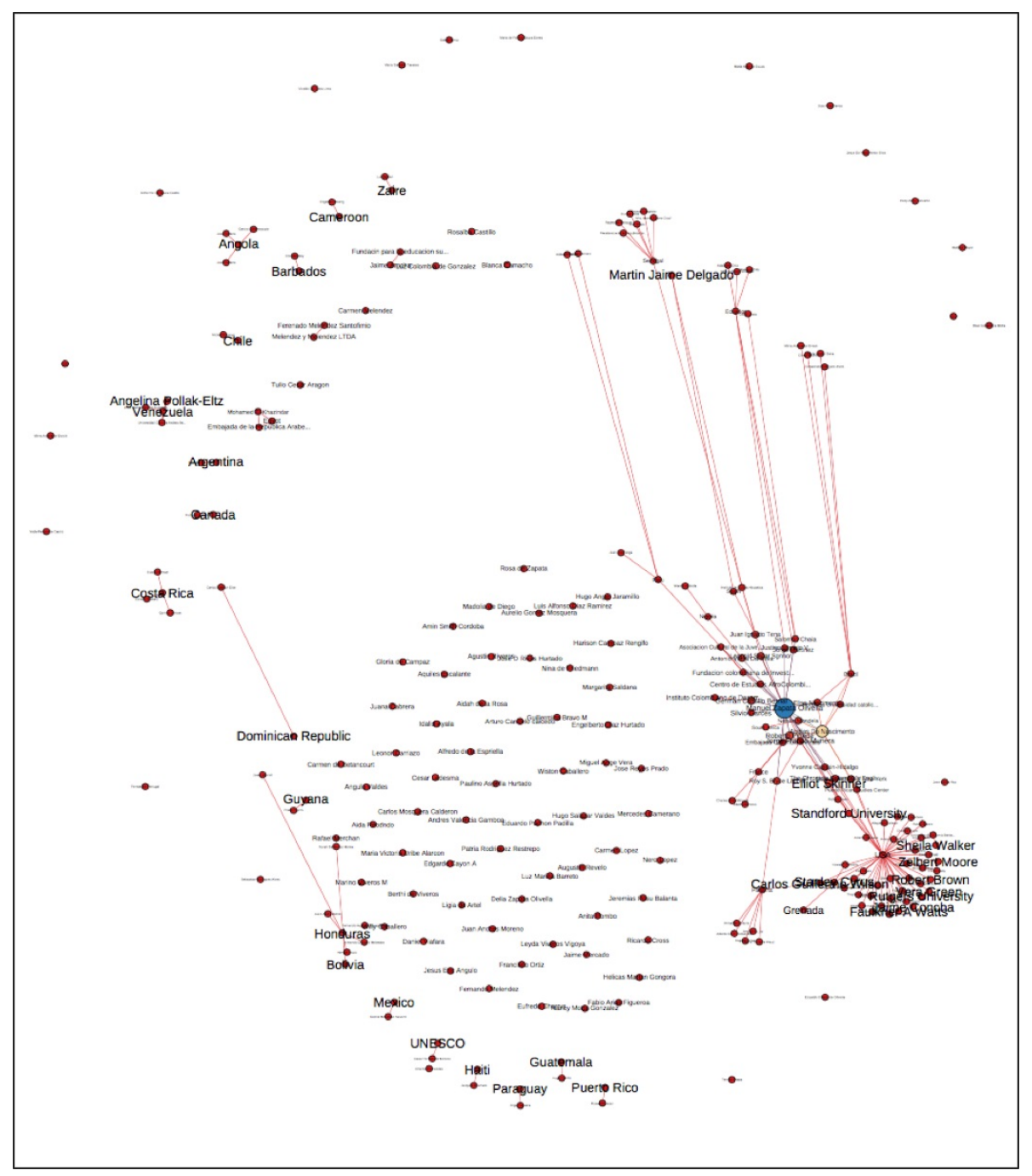

FIGURA 5

ed del Congreso de la Cultura de las Américas sin el nodo Colombia Fuente: elaboración propia 


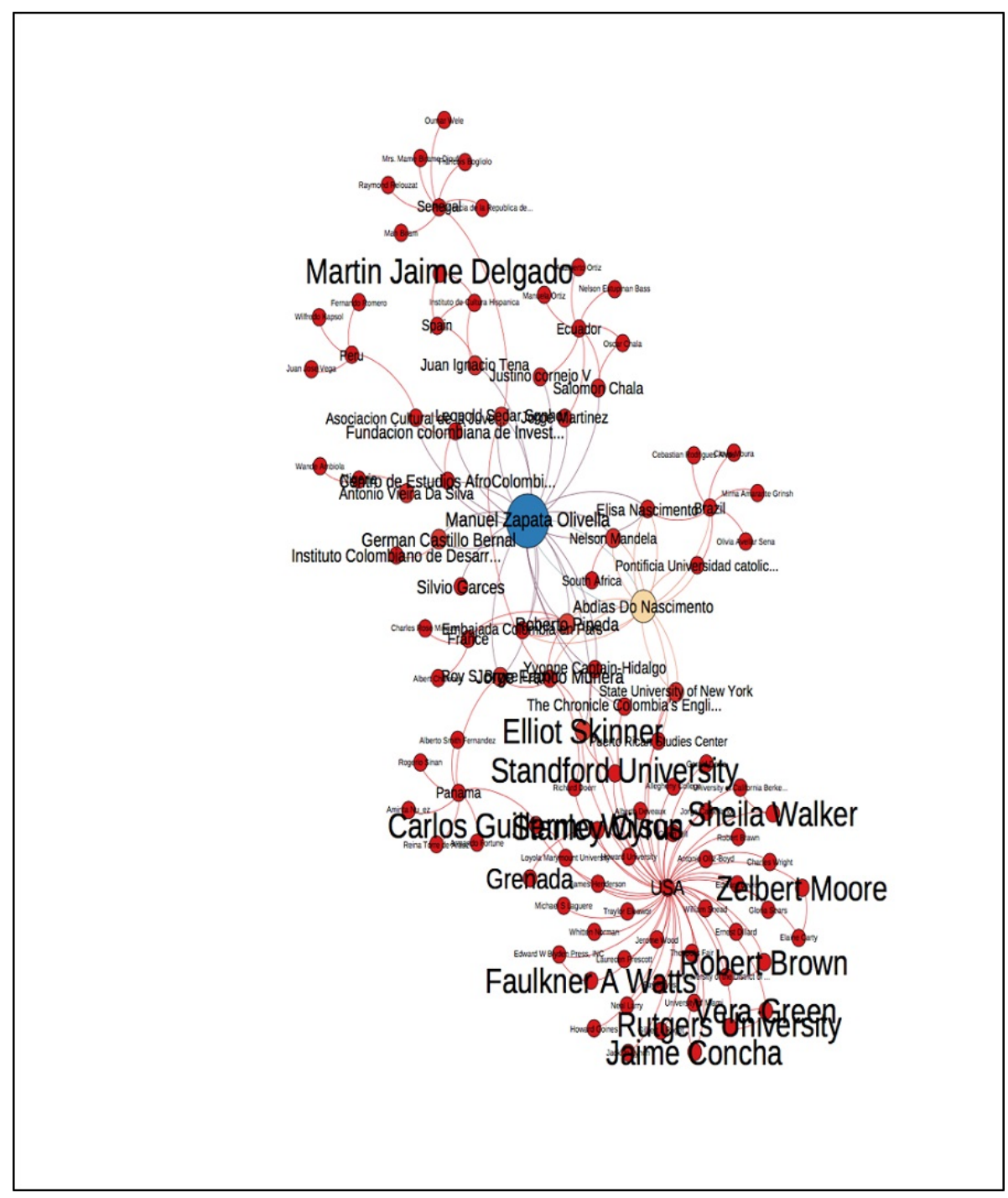

FIGURA 6

Detalle Sub-red del Congreso de la Cultura de las Américas

Fuente: elaboración propia

Los demás nodos parecen ser débiles y, en algunos casos, desconectados en el contexto de la representación computacional surgida del análisis de redes. Sin embargo, esos agentes también serán importantes en la diseminación de la agenda cultural desarrollada por el Congreso y concretada en las propuestas que emergieron al final. Asimismo, tales agentes parecen no tener mucho peso a nivel de la red particular de la que hemos hablado, pero si vamos a otras escalas tanto locales como transnacionales veremos su importancia. Por ejemplo, el caso de Quince Duncan quien participa en el Congreso, pero no parece ser tan central, se convertirá en uno de los exponentes más importantes del Afrorealismo como corriente literaria para representar lo afrodescendiente en las Américas, así como en inspiración para el movimiento afrocostarricense (Duncan). Otro ejemplo es el de Nina $S$ de Friedemann y el de Jaime Arocha. Los dos participaron en el Congreso -la primera como invitada y el segundo como asistente--, pero no son visibles en el modelo desarrollado. Sin embargo, los dos académicos comienzan a ser determinantes en el desarrollo de las políticas nacionales para el reconocimiento de las comunidades negras y afrocolombianas. Un caso similar es el de Gerardo Maloney. Este escritor y político afropanameño asistió al evento, pero los documentos no revelan la importancia y centralidad que cobrará: dos años después del congreso en Cali será presidente del segundo congreso celebrado en Panamá. Además de ocupar esa posición central en el nuevo capítulo del Congreso, en 
1994 Maloney comenzará a hacer parte del proyecto transnacional "La ruta del esclavo" patrocinado por la UNESCO y que fue fundamental para los movimientos sociales afrolatinoamericanos del siglo XXI. Éste y otros proyectos, movimientos y redes se inspirarán en la experiencia del Congreso y en las diversas formas en las que el evento desarrolló una sinergia productora de estructuras y políticas creativas de organización.

\section{Conclusiones}

La re-lectura y análisis de los archivos y documentos del Primer Congreso a través de la metodología de red nos ha permitido identificar cómo, desde los años 50, los afrolatinoamericanos han establecido diversas conexiones de solidaridad, afectividad y coordinación para alcanzar objetivos comunes: la justicia social, la equidad y la posibilidad de vivir bien en los espacios y tiempos asignados. Asimismo, los experimentos realizados nos permitieron identificar diversos nodos que, desde ciertas escalas, eran considerados débiles o, en el peor de los casos, invisibles. Sin embargo, al reconectarlos a redes culturales y, al mismo tiempo, al conectar tales redes entre sí, estos nodos comienzan a revelar su centralidad relativa y su importancia en términos de diseminación informativa. Tal es el caso de Colombia, de Manuel Zapata Olivella o de Abdias Do Nascimento quienes, en un experimento previo centrado en analizar una escala mayor, aparecían con menor importancia que nodos como Cuba o figuras como Nicolás Guillén.

Otro elemento a resaltar es el papel de los dispositivos discursivos (contenedores de cultura) que, al ser transmitidos, son adaptados a diversos contextos, generando nuevas formas de representación, dinámicas de organización y solidaridades trans-afectivas (Garland Mahler, 2018). En el caso del evento analizado aquí, las cartas y la producción textual del mismo evento produjeron conexiones que permitieron la adaptación del modelo y de la ideas artísticas y culturales en otros contextos a nivel local y regional. Muestra de ello es el desarrollo de nuevos congresos y, por lo tanto, la expansión de la red para generar procesos artístico-culturales y políticos diversos, pero conectados con la idea de lo afrolatinoamericano. Este tipo de conexiones que van de lo textual a lo contextual regularmente son nombradas en las humanidades digitales, pero no necesariamente analizadas a profundidad a través de análisis textuales estadísticos, análisis de tópicos o colecciones digitales. La adopción de las redes culturales como metodología permitirá al campo de las humanidades digitales alcanzar ese nivel tanto crítico como propositivo que reclaman autores como Risam (2019), Noble (2018) o Benjamin (2016). A partir de ello se logrará recentrar la experiencia diversa de lo humano en un mundo en el que los algoritmos - como objetos que surgen de la intersección entre el espacio computacional, los sistemas culturales y la cognición humana (Finn, 2017, p. 5)- son continuamente programados para singularizar la diversidad y riqueza simbólica de lo humano con el pretexto de alcanzar la objetividad y efectividad de lo digital.

\section{Fuente de financiación}

Este articulo es parte del proyecto First Congress of Black Culture: From Literature of Combat to Transnational Networks in the Digital Age, financiado por University of Indianapolis, Faculty Scholarship Grant Program. Agradezco a la Universidad de Indianapolis y, particularmente, a la facultad de Artes y Ciencias por el apoyo para el Desarrollo y la conclusion de este artículo.

\section{Referencias}

Garcés, S. (1977). “Carta, agosto 15, 1977 a Manuel Zapata Olivella.” Manuel Zapata Olivella Collection, Vanderbilt University, http://mzo.library.vanderbilt.edu/correspondence/essay.php?topic=congresses\&id=250 
Nascimento, A. (1976). “Carta, agosto 1, 1976 al Primer Congreso de la Cultura Negra de las Américas." Manuel Zapata Olivella Collection, Vanderbilt University, http://docrep.library.vanderbilt.edu/mzo/correspondence/ MZO.corr.Nascimento.19760801.pdf

---. (1976b). "Carta, agosto 2, 1976 a Manuel Zapata Olivella." Manuel Zapata Olivella Collection, Vanderbilt University, http://docrep.library.vanderbilt.edu/mzo/correspondence/MZO.corr.Nascimento.19770802.pdf

Primer Congreso de la Cultura Negra de las Américas (1976). "Panfleto promocional." Manuel Zapata Olivella Collection, Vanderbilt University, http://mzo.library.vanderbilt.edu/correspondence/essay.php?topic=congress es\&id=185

---. (1977a). "Primer Congreso de la Cultura Negra de las Américas." Manuel Zapata Olivella Collection, Vanderbilt University, http://docrep.library.vanderbilt.edu/mzo/correspondence/MZO.corr.ICongresoMotiv.nd.pdf

---. (1977b). “Convocatoria al Primer congreso de la Cultura Negra de las Américas." Manuel Zapata Olivella Collection, Vanderbilt University, http://docrep.library.vanderbilt.edu/mzo/correspondence/MZO.corr.ICongresoGuide lines.1977.pdf

---. (1977c). “Títulos de las ponencias." Manuel Zapata Olivella Collection, Vanderbilt University, http://docrep.libra ry.vanderbilt.edu/mzo/correspondence/MZO.corr.ICongresoPonencias.1977.pdf

---. (1977d). "Lista de participantes." Manuel Zapata Olivella Collection, Vanderbilt University, http://mzo.library.va nderbilt.edu/correspondence/essay.php?topic $=$ congresses\&id $=182$

---. (1977e). "Panfleto." Manuel Zapata Olivella Collection, Vanderbilt University, http://mzo.library.vanderbilt.edu/ correspondence/essay.php?topic $=$ congresses\&id $=180$

---. (1977f). "Lista de correo." Manuel Zapata Olivella Collection, Vanderbilt University, http://mzo.library.vanderbi lt.edu/correspondence/essay.php?topic $=$ congresses\&id $=51$

---. (1977g). "Inscripción de Abdias do Nascimento." Manuel Zapata Olivella Collection, Vanderbilt University, http: //docrep.library.vanderbilt.edu/mzo/correspondence/MZO.corr.Nascimento.197708.pdf

---. (1977h). "Resoluciones." Manuel Zapata Olivella Collection, Vanderbilt University, http://docrep.library.vanderb ilt.edu/mzo/correspondence/MZO.corr.ICongresoConcl.1977.pdf

---. (1977i). “Panfleto." Manuel Zapata Olivella Collection, Vanderbilt University, http://mzo.library.vanderbilt.edu/ correspondence/essay.php?topic $=$ congresses\&id $=94$

---. (1977j). "Plan de viaje." Manuel Zapata Olivella Collection, Vanderbilt University, http://mzo.library.vanderbilt.e $\mathrm{du} /$ correspondence/essay.php?topic $=$ congresses\&id $=177$

Zapata Olivella, M. (1976a). "Carta, septiembre 14 de 1976 a Elliot Skinner." Manuel Zapata Olivella Collection, Vanderbilt University, http://docrep.library.vanderbilt.edu/mzo/correspondence/MZO.corr.Skinner.197609 14.pdf

---. (1976b). “Carta, octubre 1, 1976) a los participantes del Congreso." Manuel Zapata Olivella Collection, Vanderbilt University, http://docrep.library.vanderbilt.edu/mzo/correspondence/MZO.corr.MZO.19761001.pdf

---. (1976c). “Carta, octubre 15, 1976 a Richard Doerr." Manuel Zapata Olivella Collection, Vanderbilt University, ht tp://docrep.library.vanderbilt.edu/mzo/correspondence/MZO.corr.Doer.19761015.pdf

---. (1977a). "Carta, 1977 a Lepoldo Sedar Senghor." Manuel Zapata Olivella Collection, Vanderbilt University, http: //docrep.library.vanderbilt.edu/mzo/correspondence/MZO.corr.MZO.1977.pdf

---. (1977b). "Carta, enero de 1977 a los participantes." Manuel Zapata Olivella Collection, Vanderbilt University, htt p://docrep.library.vanderbilt.edu/mzo/correspondence/MZO.corr.ICongresoNotice.197701.pdf

---. (1977c). "Carta de agradecimiento a participantes." Manuel Zapata Olivella Collection, Vanderbilt University, htt p://docrep.library.vanderbilt.edu/mzo/correspondence/MZO.corr.ICOngresowrapup.1977.pdf

---. (1977d). "Carta, julio 10, 1977 a Ivonne Cptain." Manuel Zapata Olivella Collection, Vanderbilt University, http: //docrep.library.vanderbilt.edu/mzo/correspondence/MZO.corr.Captain.19770710.pdf

Agudelo, C. (2010). “Génesis de redes transnacionales: movimientos afrolatinoamericanos en América central." En: Odlie Hoffmann (coord.) Politica e identidad: afrodescendientes en México y América central. México: CEMCA/ INAH/CIALC-UNAM/IRD: 65-92. 
Arriaga, E. (2018) “Temporalidades en red: representaciones artísticas de lo africano y lo afrodescendiente en la era digital.” Dorothy Odartey-Wellington. Trans-afrohispanismos. Puentes culturales críticos entre África, Latinoamérica y España. Boston: Brill Rodopi.

---. (2015) "La red de representaciones artísticas de lo afrodescendiente: tejiendo imaginarios en la era digital: Colombia, Canadá y Guinea Ecuatorial." En: Silvia Valero y Alejandro Campos García (Eds). Identidades políticas en tiempos de afrodescendencia: auto-identificación, ancestralidad, visibilidady derechos. Buenos Aires: Corregidor.

Barabasi, A.L. (2002). Linked: The New Science of Networks. Cambridge, MA: Perseus Publishing.

Benjamin, R. "Catching Our Breath: critical Race STS and the Carceral Imagination." Engaging Science, Technology and Society, vol. 2, 2016. DOI:10.17351/ests2016.70

Castels, M. (1996). The Rise of the Network Society. New York: Wiley-Blackwell.

Delfín, M. (2013). "The Promise of Cultural Networks in Latin America: Towards a Research Framework for the Study of Region-Specific Cultural Network Ecosystem." Cultural Trends 21(3): 239-248.

Díaz-Granados, J. L. (2003). Manuel Zapata Olivella, su vida y su obra. Recuperado de https://manuelzapataolivella .co/pdf/MZO-SuVidayObra.pdf

Dzidzienyo, A. (1978). "Activity and Inactivity in the Politics of Afro-Latin America." SECOLAS Annals 9: 48-61.

Escobar, A. (2015). Territorios de diferencia. Lugar, movimientos, vida, redes. Popayán: Universidad del Cauca.

Finn, E. (2017). What Algorithms Want. Cambridge, M.A.: Massachusetts Institute of Technology.

Fontaine, P. M. (1980). "Research in the Political Economy of Afro-Latin America." Latin America Research Review $15(2): 11-41$.

Garland Mahler, A. (2018). From the Tricontinental to the Global South. Race, Radicalism, and Transnational Solidarity. Durham N.C: Duke, University Press.

Granovetter, M. (1973). “The Strength of Weak Ties.” American Journal of Sociology 78(6): 1360-1380.

Heylighen, F. (2009). “Complexity and Self-Organization.” In Marcica Bates \& Mary Niles Maack. Encyclopedia of Library and Information Sciences. New York: Taylor \& Francis.

Mera Villamizar, D. (2008). “Marino Viveros y el color en 1943.” Proclama del Cauca. Recuperado de: https://www. proclamadelcauca.com/marino-viveros-y-el-color-en-1943/

Moretti, F. (2005). Graphs, Maps and Trees. Abstract Models for a Literary History. New York-London: Verso.

Nascimento, A. do (1979) Brazil. Mixture or Massacre? Essays in the Genocide of a Black People. Dover, M.A.: The majority press.

Noble, Safiya U (2018). Algorithms of Opression: How Search Engines Reinforce Racism. New York University.

Ortiz, F. (1944a) "Se estableció en México el Instituto Internacional de Estudios Afroamericanos." Letters from Instituto Internacional de Estudios Afroamericanos to W.E.B. Du Bois. 1-2. Recuperado de https://credo.library.umass.e $\mathrm{du} / \mathrm{view} /$ full/mums312-b103-i200

---. (1944b) "Lista" Letters from Instituto Internacional de Estudios Afroamericanos to W.E.B. Du Bois. 1-2. Recuperado de https://credo.library.umass.edu/view/full/mums312-b103-i201

Reid Andrews, G. (2016). Afro-Latin America. Black Lives, 1600-2000. Harvard University Press

Peter, C. (2006). “Strong Links are Important but Weak Links Stabilize Them." Trends in Biochemical Science 29 (7): 331-334. Recuperado de https://www.sciencedirect.com/science/article/abs/pii/S0968000404001240

Pisano, P. (1977). Liderazgo politico 'negro' en Colombia, 1943-1964. Bogotá: Universidad Nacional de Colombia.

Prescence Africaine (1956). The First International Conference of Writers and Artists. Paris: Prescence Africaine. Recuperado de https://www.freedomarchives.org

Prescott, L. (2007). Journeying Through Jim Crow. Spanish American Travelers in the United States during the Age of Segregation. Latin American Research Review 42 (1) February, 3-28.

Prescott, L. \& Tilis, A. (2006). "Introducción. Manuel Zapata Olivella." Afro-Hispanic Review, 25 (1), 9-14.

Ratcliff, A. (2008). "Black Writers of the World, Unite! Negotiating Pan-African Politics of Cultural Struggle in AfroLatin America." The Black Scholar 37 (4), 27-38. 
Reynoso, C. (2011). Redes sociales y complejidad. Bueno Aires: Paidós.

Risam, R. (2019). New Digital Worlds. Boston: North Western University Press.

Suárez, J. L., Ben McArthur, and Adriana Soto-Corominas (2015). "Cultural Networks and the Future of Cultural Analytics." Proceeedings of Culture and Computing. 95-98

Valderrama Rentería, C. (2013). “Folclore, raza y racismo en la política cultural e intelectual de Delia Zapata Olivella. El campo político-intelectual afrocolombiano” Revista CS 12, 259-296. Recuperado de https://doi.org/10.18 $046 /$ recs.i12.1674

Zapata Olivella, M. (2000) Pasión Vagabunda. Bogotá: Ministerio de Cultura.

----(1999). Las claves mágicas de América. 2da edición. Bogotá: Plaza y Janes.

--- (1990). Levántate mulato. Por mi raza hablará el espiritu. Bogotá: Rei Andes.

---- (1956). “¿Qué sabemos de los negros colombianos?” Cromos 13 (agosto): 32-33, 44.

---- (1953). He visto la noche. Medellín: Los Andes.

\section{Notas}

* Artículo de investigación. Producto de la investigación First Congress of Black Culture: From Literature of Combat to Transnational Networks in the Digital Age, financiado por University of Indianapolis, Faculty Scholarship Grant Program

1 El concepto "afrolatinoamericano" comienza a ser acuñado desde la década de los años 70, inspirado por la movilización política negra de la época. Surge de una visión hemisférica que buscaba conectar y hacer visibles las identidades, individuos y comunidades existentes en los diversos países de las Américas y del Caribe. Al respecto, ver Anani Dzidzienyo (1978), Pierre-Michel Fontain (1980) y George Reid Andrews (2016) entre otros.

2 Los estudios sobre la cultura afrolatinoamericana del siglo XX se han centrado fundamentalmente en países del Caribe como Cuba, Puerto Rico, República Dominicana, Haití o en países como Brasil en los que la población negra de origen africano, así como sus contribuciones, son imposibles de ocultar. Asimismo, figuras como Nicolás Guillén, Alejo Carpentier Manuel Moreno Franginals, Fernando Ortiz, Rene Depreste, entre otros, han sido vistos como centrales en la diseminación de los valores culturales afrolatinoamericanos. Sin embargo, países andinos/caribeños como Colombia o figuras como Manuel Zapata Olivella no han comenzado a ser revisitados a nivel continental hasta hace menos de tres décadas.

3 Esta distinción se refiere a productores culturales (artistas visuales, literarios, teatrales, musicales, etc.) que han tenido formación profesional en institutos, academias o universidades, y aquellos que han desarrollado su producción artística sin formación previa.

4 Es imposible entender lo que ha sido llamado afrolatinoamericano sin la comprensión de las relaciones, algunas veces tensas, otras complementarias y otras completamente superpuestas entre el sistema cultural indígena, el negro-africano y el europeo. Así mismo, es importante recordar la importancia de lo multi-temporal en cruce y coexistencia para la formación de imágenes culturales como las de lo afrodescendiente y lo afrolatinoamericano en particular.

5 Wandora es una aplicación de escritorio usada para coleccionar, guardar, manipular, analizar y publicar información, particularmente datos asociativos o redes de información. La herramienta produce mapas de tópicos o redes de tópicos que le permiten al investigador entender cómo se establecen las relaciones informativas entre los tópicos que emergen del análisis. Ver http://wandora.org/www/

6 Python es un lenguaje de programación basado en programación orientada hacia objetos. Es decir, en este tipo de lenguajes los programas creados se dividen en objetos en vez de dividirse en funciones. Uno de los muchos paquetes creados en Python es el Natural Language Toolkit (NLTK), usado para crear programas y analizar datos basados en lenguaje natural. Para más información ver:https://www.python.org/ y http://www.nltk.org/

7 Gephi es una plataforma abierta de visualización. Funciona en Windos, McOs y Linux. Ésta es una herramienta diseñada para visualizar bases de datos y redes en forma de grafos. Tiene funcionalidades estadísticas que miden, entre otras, la centralidad relativa, el coeficiente de conexión, la dimensionalidad de la red, y la formación de comunidades. Estas operaciones se pueden aplicar a las redes analizadas para ver patrones y relaciones. Para mayor información sobre la herramienta, ver https://gephi.org/

8 A saber: a) emergen como sistemas impredecibles generados entre el orden (lo predecible) y el desorden (lo impredecible); b) cuentan con numerosas partes que interactúan de formas diversas; c) las interacciones entre las partes no son lineales, lo que quiere decir que no siempre se establece una interacción de causa y consecuencia; d) hay una tendencia a la auto-organización a partir de la cual se establecen estados de cambio y estabilidad con relación al 
sistema mismo (organización local) y con relación al medio ambiente (organización global); e) las partes del sistema co-evolucionan y establecen una sinergia; y f) a partir de la sinergia y de la co-evolución, se producen emergencias de patrones o de nuevos sistemas que comienzan a crear nuevas formas de auto-organización.

9 Estas dos iniciativas anteceden la formación del Instituto Internacional de Estudios Afroamericanos, fundado en México en 1945, bajo la dirección de Fernando Ortiz y Gonzalo Aguirre Beltrán. Aunque no son comparables, es importante resaltar el interés transnacional en lo africano y Afrodescendiente debido a la postguerra, a los procesos de descolonización en África y a las denuncias y activismo del movimiento de los derechos civiles en los Estados Unidos. Zapata Olivella será no solo testigo de estos eventos sino protagonista de sus propias iniciativas. Ver: Ortiz (1944) "Se estableció.....” y “Lista”.

10 Al respecto, ver el excelente trabajo de Carlos Alberto Valderrama Rentería (2013) relativo a Delia Zapata y su participación en la intelectualidad afrocolombiana a través de la danza y el folklore.

11 Díaz-Granados muestra cómo el joven Zapata Olivella tiene que hacer trabajos diversos como "albañil, actor, conferencista, auxiliar de anestesista, funcionario en un sanatorio psiquiátrico” (Díaz-Granados, 2003, p.19), entre otros. La diversidad de ocupaciones le permite a Zapata Olivella extender una red no sólo cultural sino espistemológica a través de la cua identificará las complejas bases culturales de las Américas.

12 La lectura distante es un concepto acuñado en la historia de la literatura y, particularmente, en las humanidades digitales propuestas por Franco Moretti (2005). La lectura distante se diferencia de la lectura cercana porque en la primera usamos herramientas computacionales y modelos que ayudan a la interpretación del material leído. La lectura cercana, por otro lado, es el tipo de lectura usado tradicionalmente en las ciencias sociales y humanas.

13 Ver cita 7 donde se explica cómo funciona la herramienta

14 Es innegable la importancia de Brasil en el desarrollo de la tradición afrolatinoamericana. Las afirmaciones respecto a su debilidad en la red del Primer Congreso tienen que ver con la evidencia encontrada en las cartas y documentos referentes al mismo. Tal será la importancia de ese país que se convertirá en la sede del tercer capítulo, mostrando su poder real en el contexto del mundo cultural y del activismo afrolatinoamericano.

15 El texto original está en inglés. La traducción es mía.

\section{Licencia Creative Commons CC BY 4.0}

Cómo citar este artículo: Arriaga Arango, D. (2020). Redes Culturales Afro-Latinoamericanas. El caso del Primer Congreso de la Cultura Negra de las Américas. Universitas Humanistica, 89. https://doi.org/10.11 144/Javeriana.uh89.rcal 